\title{
Meiotic Studies in Cosmos sulphureus Cav.
}

\author{
Shailja Kumari and M. C. Sidhu ${ }^{1}$ \\ Department of Botany, Panjab University, Chandigarh, India \\ 1'Author for Correspondence: (mcsidhu@hotmail.com) \\ Received November 12, 2012; accepted December 10, 2012
}

\begin{abstract}
Cosmos sulphureus Cav. was studied with respect to its meiotic behavior. It has been observed that this plant species is a diploid with the chromosome number of $n=12$. The course of meiosis was normal in most of the cells but some meiotic irregularities have also been observed.
\end{abstract}

KEYWORDS: Asteraceae, Chromosome number, Cosmos sulphureus, Meiotic abnormalities

Cosmos sulphureus Cav. [Syn. Bidens sulphurea (Cav.) Sch. Bip.] is a member of the family Asteraceae. It is cultivated as an ornamental plant or it has been found as growing wild weeds along the roadsides and other undisturbed areas (Fig. 1a). The plant is ca $1 \mathrm{~m}$ high and has compound leaves. It is a subshrub and bears actinomorphic yellow flowers (Sakuragui et al. 2011). Melchert (1968) designated this species as a weed. Besides its antibacterial, antifungal, antiviral and antiinflammatory properties, the flower heads of this plant are used as an eco-friendly dye in woolen industry (Jansen and Cardon 2005; Kale et al. 2006). Xiaolan and Maoxue (1987) while studying the chromosome number of ten species of the Asteraceae and the karyotype of eight species have reported the chromosome number of $2 n=24$. Other researchers have also reported the meiotic behavior of this species and found the course of meiosis to be usually normal. However, chromosomal irregularities have also been observed in some other cases. The purpose of the present study is to look at the chromosome configurations during the various stages of meiosis in the material collected in Chandigarh.

\section{Materials and Methods}

The material for the present study was collected on campus, Panjab University, Chandigarh. Immature flower buds at appropriate time and stages were collected for meiotic study. They were fixed in 3:1 of ethanol:acetic acid solution for $24 \mathrm{hrs}$. Later on it was shifted to $70 \%$ ethanol and preserved at low temperature till further use. The anthers were squashed in $2 \%$ acetocarmine stain. The slide was then screened under the microscope to find out the chromosomes at different stages of meiosis. The chromosome number was recorded from maximum possible cells. The photomicrographs of selected cells having countable number of chromosomes were taken.

\section{Results and Discussion}

The meiotic observations on Cosmos sulphureus Cav. showed the presence of 12 bivalents, when the course of meiosis was normal (Fig. 1b). The present finding for the chromosome number in this species was in conformity with Sugiura (1939), Melchert (1968), and Gupta and Gill (1984) designated as diploid. However, meiotic abnormalities in the form of univalents and trivalents have also been reported in some cells (Fig. 1c-e). According to Narain (1982) Cosmos sulphureus cultivar 'OrangeRuffles' was a diploid and had the basic chromosome number of $x=12$. The meiotic preparations of this cultivar have shown the presence of variable number of univalents which has corroborated our findings of chromosome irregularities in the form of univalents in Cosmos sulphureus. Some homologous chromosomes could not pair and results in the formation of univalents and trivalents. The chromosomal segregation at anaphase I stage was normal (Fig. 1f). Therefore, the presently studied population has been found to be diploid with $n=12$ chromosomes along with some meiotic abnormalities in the form of univalents and trivalents.

ACKnOWLedgement. The authors are grateful to the Chairperson, Department of Botany, Panjab University, Chandigarh for providing the necessary facilities to carry out this piece of work.

\section{Literature Cited}

Gupta, R. C. and Gill, B. S. 1984. Cytological Investigations on Central Indian Compositae. Cytologia 49: 427-435.

Jansen, P. C. M. and Cardon, D. 2005. Dyes and Tannins; Plant resources of Tropical Africa 3. PROTA Foundation/ Backhuys Publishers/CTA Wageningen, Netherlands.

Kale, S., Naik, S. and Deodhar, S. 2006. Utilization of Cosmos sulphureus Cav. flower dye on wool using mordant combinations. Nat. Prod. Rad., 5(1): 19-24.

Melchert, T. E., 1968. Systematic Studies in the Coreopsidinae: Cytotaxonomy of Mexican and Guatemalan Cosmos. Amer. Journ. Bot. 55(3): 345-353.

Narain, P., 1982. Desynapsis in a cultivar of Cosmos sulphureus Cav. Curr. Sci. 51(18): 901.

Sakuragui, C. M., Alves, E. M., Lorenzetti, E. R., Janunzzi, A. M., Borges, R. A. X. and De Toledo, V. A. 2011. Bee Flora of an Insular Ecosystem in Southern Brazil. Journ. Bot. Res. Inst. Texas, 5(1): 311 - 331.

Sugiura, T., 1939. Studies on the chromosome numbers in 
higher plants III. Cytologia, 10(1-2): 205-212.

Xiaolan, W. and Maoxue, L. 1987. Observation of chromosomes on 10 Compositae species. Journ. Wuhan Bot. Res., 5(2): 111-118.

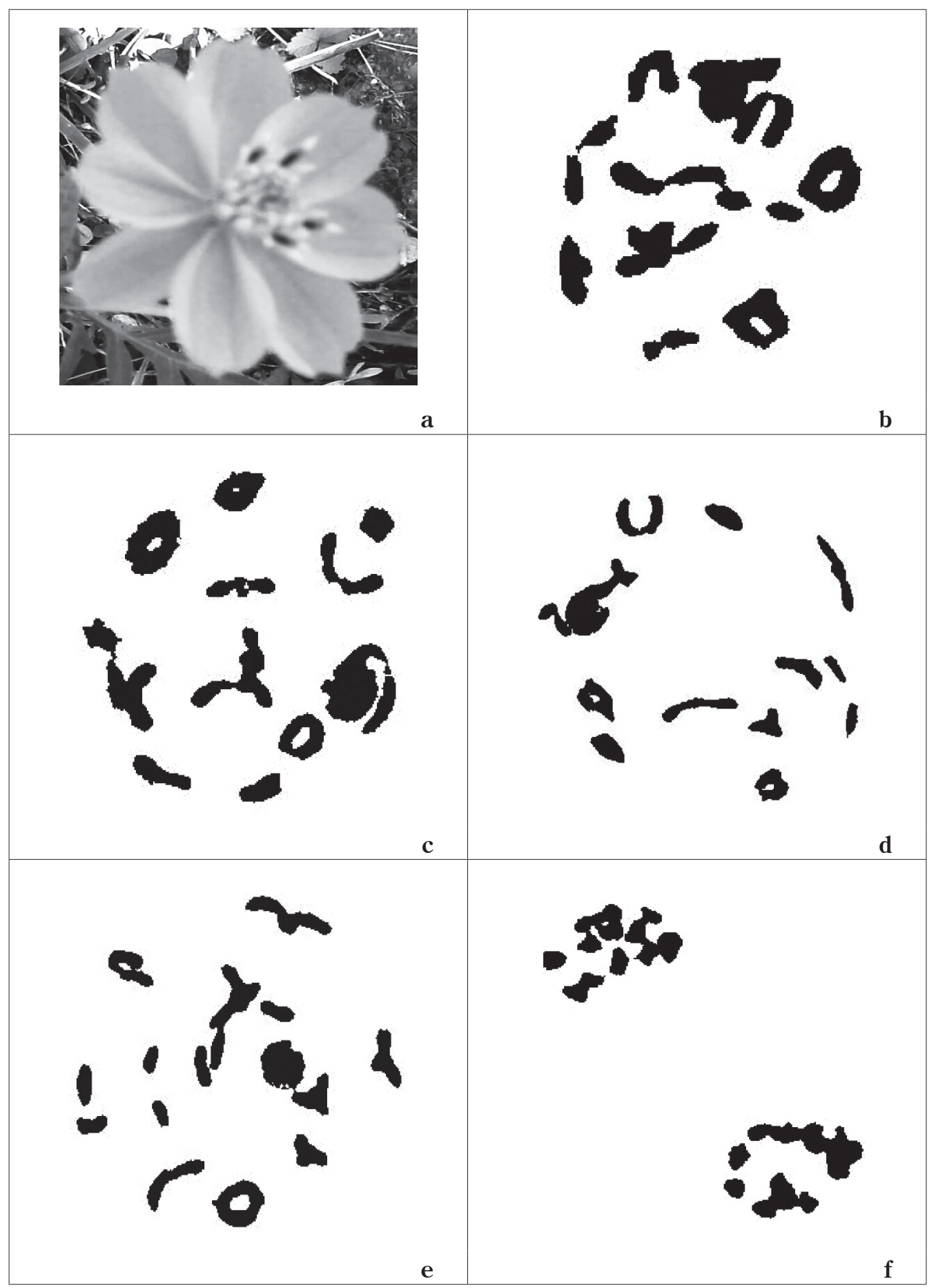

Fig. 1. Flower and meiotic chromosome configulations of Cosmos sulphureus. a. Flower. b. $12_{\text {II }}$ c. $11_{\text {II }}+2_{\text {I }}$ d. $2_{\text {III }}+7_{\text {II }}+4_{\text {I }}$. e. $9_{\text {II }}+6_{\text {I. }}$ f. $12-12$. 